\title{
Brewing fuels in a solar furnace
}

\author{
By Arthur L. Robinson, with contributions by Corinna Wu \\ Feature Editor Aldo Steinfeld
}

$\mathbf{R}^{\mathrm{e}}$ elying on existing concentrated solar power (CSP) technology for the thermal energy to drive it, solar thermochemical production of synthesis gas (syngas) anchors a promising solar route to liquid hydrocarbon fuels. Cyclical two-step oxidation-reduction (redox) reactions with water and carbon dioxide as feedstocks and a metal oxide as the redox material yield the syngas constituents hydrogen and carbon monoxide. Syngas itself is the precursor to the final energy product, conventional liquid fuels such as diesel, kerosene, and gasoline. Subsequent production steps rely on proven conversion technologies such as the Fischer-Tropsch and methanol-to-gasoline (MTG) processes, although purified hydrogen could itself fuel an alternative hydrogen economy.

The impact of solar thermochemical fuels could be spectacular. With renewable liquid fuels derived from the sun, water, and carbon dioxide, many countries would benefit from dramatically increased energy security and financial stability. And hydrocarbon fuels are the only potential product family that could consume $\mathrm{CO}_{2}$ feedstock at a level comparable to current emissions, making the entire fuel production-to-combustion cycle, in principle, carbon-neutral. The ability to use the existing global storage and distribution infrastructure for liquid fuels would add an important economic and logistical plus. "Renewable liquid fuels would be pretty special," said James Miller of Sandia National Laboratories' Sunshine-to-Petrol project.

While researchers seeking to produce fuels from the sun have a full menu of options (electrochemical, photochemical, and thermochemical), proponents of the two-step, redox approach cite the favorable thermodynamics arising from high-temperature operation and the full utilization of the solar spectrum that in principle could lead to solar-to-fuel energy conversion efficiencies - defined as the ratio of the calorific value of the syngas produced to the solar energy input-above $30 \%$. In addition, there is no need for separation of a combustible fuel-oxygen mixture, a tricky problem for one-step methods.

On paper, the two-step cyclic process seems simple: (1) Concentrated solar radiation heats the metal oxide to well above $1000^{\circ} \mathrm{C}$, thereby driving its endothermic reduction and releasing oxygen as the product; (2) the reduced oxide is cooled to $1000^{\circ} \mathrm{C}$ or below while steam or carbon dioxide flows through, re-oxidizing it and liberating hydrogen or carbon monoxide as the respective products. The net reaction is water or carbon dioxide splitting.

Making the technology practical and cost-effective poses considerable challenges. Fortunately, the most expensive technology already exists. Like the CSP solar farms that provide the high-temperature for electricity generation by a steam turbine, solar thermochemical processes rely on a large field of solar collectors to focus the light into a reactor vessel sitting atop a tower. The solar-collector field comprises individual heliostats that together can track the sun, concentrate the sunrays several thousandfold, and place the high-flux solar radiation where it is needed to drive the endothermic transformation.

That the heliostat field is expensive raises the performance bar for the rest of the solar thermochemical plant. "Efficiency is always the most important thing," said Christian Sattler of the German Aerospace Center in Cologne, which is testing a pilot plant with a solar radiative thermal input of $100 \mathrm{~kW}$ for producing hydrogen from water at the solar tower of the Plataforma Solar de Almería, Spain. "Higher efficiency means fewer mirrors are needed, leading to a cheaper installation," Sattler said.

Redox materials must function with high efficiency at extreme temperatures up to $1500^{\circ} \mathrm{C}$ or more, while remaining stable against performance-damaging morphological changes. The reactor vessels themselves must resist melting or reacting at the highest temperatures, tailor the concentrated solar irradiation for uniform reactor temperature, facilitate rapid temperature changes of several hundred degrees between the two reaction steps but not waste the heat generated, and manage the flow of gaseous feedstocks to match reaction speeds and of purge gases for rapid cycling. And these interdependent components all have to work together for many thousands of cycles annually.

Among the numerous redox material candidates, there is as yet no clear winner, in part because the performance requirements (favorable thermodynamics, fast kinetics, and morphological stability) tend to be at odds with one another. To find the optimum compromise, researchers have sought new compositions that synergistically combine the good properties of 
(a) Reduction $\mathrm{CeO}_{2} \rightarrow \mathrm{CeO}_{2-\delta}+\frac{\delta}{2} \mathrm{O}_{2}$

Concentrated Solar Radiation
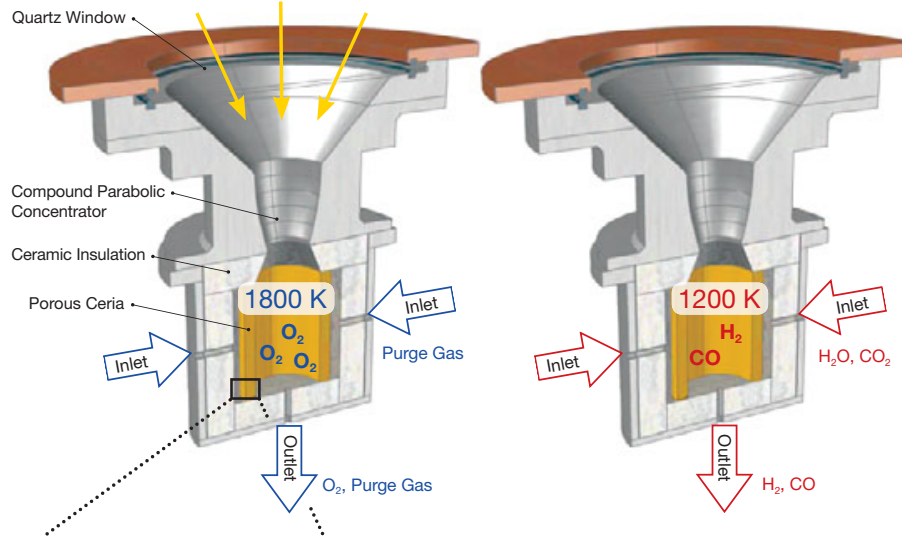

(b) Oxidation

$\mathrm{CeO}_{2-\delta}+\delta \mathrm{H}_{2} \mathrm{O} \rightarrow \mathrm{CeO}_{2}+\delta \mathrm{H}_{2}$ $\mathrm{CeO}_{2-\delta}+\delta \mathrm{CO}_{2} \rightarrow \mathrm{CeO}_{2}+\delta \mathrm{CO}$

A solar reactor for the two-step $\mathrm{CeO}_{2} /$ $\mathrm{CeO}_{2-\delta}$ redox solar thermochemical cycle. Concentrated solar radiation passing through a windowed aperture enters a cavity-receiver containing a reticulated porous ceramic (RPC) foam made of ceria. (a) Efficient solar absorption through multiple internal reflections transfers heat directly to the reaction site to drive the endothermic reduction, releasing oxygen. (b) Reacting gases $\mathrm{H}_{2} \mathrm{O}$ and/or $\mathrm{CO}_{2}$ flow radially across the porous ceria to drive the exothermic oxidation, while product gases $\mathrm{H}_{2}$ and/or $\mathrm{CO}$ exit the cavity through an axial outlet port. Inset: Ceria RPC. Courtesy of ETH Zürich.

the constituents with morphologies conducive to reaction efficiency. For example, the poor reaction kinetics of iron oxide can be improved by the addition of other metals, such as cobalt or nickel, to create metal-substituted ferrites $\left(\mathrm{M}_{\mathrm{x}} \mathrm{Fe}_{3-\mathrm{x}} \mathrm{O}_{4}\right)$.

At Sandia, a further step is to react the ferrite with zirconia. Dissolution of the iron in the zirconia allows oxygen to move through the solid, thereby improving the kinetics. "You get the best of two worlds," said Sandia's Miller, combining the favorable thermodynamics of iron with the transport benefits of the zirconium. At the same time, the zirconium stabilizes the structure against morphological changes.

At the University of Colorado, Alan Weimer and his colleagues react cobalt ferrite with alumina during the reduction cycle to make stable aluminate intermediates $\left(\mathrm{CoAl}_{2} \mathrm{O}_{4}\right.$; $\left.2 \mathrm{Fe}_{2} \mathrm{AlO}_{4}\right)$. During the oxidation stage, the ferrite and alumina are returned along with hydrogen product. Weimer cites a 150 $200^{\circ} \mathrm{C}$ temperature decrease for reduction, which may allow the use of metal alloy reactor vessels in place of ceramics. To promote radiative heat transfer, gas flow, and fast kinetics, the Colorado group creates highly porous ( $>80 \%$ voids) alumina nanostructures and then coats them with cobalt ferrite.

Many researchers are looking closely at ceria $\left(\mathrm{CeO}_{2}\right)$ redox materials because they display rapid fuel-production kinetics and high selectivity. Gilles Flamant of the French CNRS PROMES laboratory in Odeillo points out that very high temperatures are required to reduce $\mathrm{CeO}_{2}$ to $\mathrm{Ce}_{2} \mathrm{O}_{3}$, but using nonstoichiometric material can bring the temperature down. It can

further avoid technical hitches such as melting and vaporization. Sossina Haile of the California Institute of Technology explains how the nonstoichiometric composition throughout the cycling is key: "Ceria can liberate a large fraction of its oxygen atoms while retaining its fluorite structure at temperatures of $1500^{\circ} \mathrm{C}$ to $1600^{\circ} \mathrm{C}$, rendering ceria-based cycles plausible."

Wojciech Lipinski at the University of Minnesota sums up the virtues of these materials: "They display the desired reduction/ oxidation properties with the use of macro-, micro-, and nanoporous structures to facilitate gas flow and thermal energy transport through the solid." A team led by Aldo Steinfeld at ETH Zürich and the Paul Scherrer Institute in Switzerland recently has verified these advantages in its report of simultaneous solar splitting of both water and $\mathrm{CO}_{2}$. Record solar-to-fuel energy conversion efficiencies of $3.5 \%$ peak and $1.7 \%$ average were reported for $\mathrm{CO}_{2}$ conversion to $\mathrm{CO}$ in a solar reactor containing reticulated porous ceria. The Swiss team is also investigating the volatile $\mathrm{ZnO} / \mathrm{Zn}$ redox cycle, which promises high efficiencies, provided that $\mathrm{Zn} / \mathrm{O}_{2}$ recombination can be avoided.

Reactor designs can impose their own requirements on materials, according to whether the concentrated sunlight is moved to the redox material or whether the material is moved to the sunlight. "We're avoiding mechanical contraptions that move at high temperature," said Weimer at Colorado, where researchers place the active porous materials in multiple tubes arranged axially in the reactor vessel and switch the sunlight from one set of tubes to another by adjusting the focus of the mirror field.

The German Aerospace Center's Hydrosol project takes a similar tack by using two different reactor vessels operating in parallel and switching a subset of heliostats between the two as the reaction cycle alternates from high-temperature reduction to low-temperature oxidation. At the University of Florida, James Klausner and his co-workers are developing a solar reactor that operates under vacuum during the thermal reduction step, bringing the required temperature down and reducing inert gas usage. As in the Hydrosol project, two reactors operate side by side.

At the other extreme, Sandia's Sunshine-to-Petrol project is based on a reactor vessel dubbed the CR5 that counter-rotates multiple staggered rings with thin fins of monolithic, porous redox material through the illuminated zone to change the temperature. Radiative transfer from a heated fin to a cooler neighboring fin serves as an efficiency-boosting heat recuperation mechanism. And, although different in design from CR5, a rotating structure in Minnesota's reactor also re-uses heat from the hotter parts to preheat the colder parts in advance of the reduction reaction.

While a high-volume solar thermochemical fuel technology is still a decade or more away, the prospects for success are highly favorable, argue proponents, pointing to existing solar fuel demonstration and commercial CSP plants. Moreover, a 2011 report for the US Department of Energy (DOE) by TIAX LLC that analyzed several thermochemical technologies for splitting water to produce hydrogen concluded that the solar thermochemical two-step, redox cycle was most likely to meet DOE cost goals for 2015 and 2025. 